\title{
A SUFFICIENT CONDITION FOR COUNTABLE-SET APOSYNDESIS
}

\author{
DONALD E. BENNETT ${ }^{1}$
}

\begin{abstract}
In this paper a stronger form of aposyndesis is defined and continua with this property (strongly aposyndetic) are shown to be countable-set aposyndetic. Although every continuum which is a product of nondegenerate continua is countable-set aposyndetic, it is established that no product of nondegenerate continua is strongly aposyndetic.
\end{abstract}

Throughout this paper a continuum is a compact connected metric space. Let $M$ be a continuum. If $N$ is a subcontinuum of $M$, the interior of $N$ in $M$ will be denoted by int $N$ and the boundary of $N$ in $M$ by $\operatorname{Bd} N .^{2}$ A continuum $M$ is aposyndetic at a point $p$ if for each point $q$ in $M-\{p\}$ there is a subcontinuum $N$ in the complement of $\{q\}$ such that $p \in$ int $N$ [3]. If the $\{q\}$ above is replaced by a finite (countable closed) set then $M$ is said to be finitely (countable-set) aposyndetic at $p$. A continuum is aposyndetic (finitely aposyndetic) (countable-set aposyndetic) if it has the given property at each point [7].

This familiar property can be strengthened as follows.

Definition. A decomposable continuum $M$ is strongly aposyndetic provided that for any pair of proper subcontinua $H$ and $K$ such that $M=H \cup K$, each of $H$ and $K$ is aposyndetic.

It is easily seen that each strongly aposyndetic continuum is aposyndetic and there are numerous elementary examples of aposyndetic continua which fail to be strongly aposyndetic. The following two theorems established sufficient conditions for subcontinua of a strongly aposyndetic continuum to be aposyndetic. The first theorem is an immediate consequence of the definition.

THEOREM 1. If $A$ is a nonseparating subcontinuum of a strongly aposyndetic continuum $M$ and int $A \neq \varnothing$, then $A$ is aposyndetic.

Received by the editors October 15, 1970.

AMS 1970 subject classifications. Primary 54F20, 54F15; Secondary 54B10.

Key words and phrases. Aposyndetic, countable-set aposyndetic, continuum, product of continua, irreducible continua, decomposable continua.

1 The author gratefully acknowledges the suggestions of the referee.

${ }^{2}$ For definitions of unfamiliar terms and phrases, see [4] and [9]. 
THEOREM 2. Let $M$ be a strongly aposyndetic continuum. Then each nondegenerate subcontinuum of $M$ with totally disconnected boundary is aposyndetic.

Proof. Let $N$ be a nondegenerate subcontinuum of $M$ such that Bd $N$ is totally disconnected.

Case I. Suppose there is a $p \in($ int $N)$ such that $p$ does not separate $M$. There is an open set $V$ in $M$ such that $p \in V \subset$ int $N$ and $M-V$ is connected [8]. Since $N$ and $M-V$ are proper subcontinua of $M$ and $M=N \cup(M-V)$ it follows that $N$ is aposyndetic.

Case II. Suppose each $x \in($ int $N)$ separates $M$. Let $x \in($ int $N)$ and $U$ and $V$ be disjoint open sets in $M$ such that $M-\{x\}=U \cup V$. If $N-\{x\}$ is connected, assume $N-\{x\} \subset U$. Thus $N \subset(U \cup\{x\})$ and since $x \in($ int $N)$ it follows that $x \notin \mathrm{Cl} V$. Since this is a contradiction, each point of (int $N$ ) separates $N$.

Let $L$ be a nondegenerate subcontinuum of $N$. Since $L \cap($ int $N) \neq \varnothing$, $L$ contains an uncountable number of separating points of $N$. It follows that $N$ is a dendrite [9, Theorem 1.1, p. 88]. Therefore $N$ is aposyndetic.

In [1] unicoherence was shown to be a sufficient condition for an aposyndetic continuum to be finitely aposyndetic. The following theorem establishes a sufficient condition for an aposyndetic continuum to be countable-set aposyndetic.

THEOREM 3. Suppose $M$ is a continuum which is strongly aposyndetic. Then $M$ is countable-set aposyndetic.

Proof. Suppose $M$ is not countable-set aposyndetic. There is a point $p \in M$ and a countable closed set $S$ in $M-\{p\}$ such that $M$ is not aposyndetic at $p$ with respect to $S$. This property on " $p$ " is inducible. Thus by the Brouwer Reduction Theorem [9, Theorem 11, p. 17] there is a closed subset $S^{\prime}$ of $S$ such that $M$ is not aposyndetic at $p$ with respect to $S^{\prime}$ but $M$ is aposyndetic at $p$ with respect to any proper closed subset of $S^{\prime}$. Let $s$ be an isolated point of $S^{\prime}$. Then there is a subcontinuum $H$ in $M-$ $\left(S^{\prime}-\{s\}\right)$ such that $p \in$ int $H$. Clearly $s \in H$.

Case I. $p$ does not separate $M$. Since $M$ is aposyndetic, there is an open set $U$ such that $p \in U \subset$ int $H$ and $M-U$ is connected [8]. Then $H$ and $M-U$ are proper subcontinua and $M=H \cup(M-U)$; therefore $H$ is aposyndetic. There is a subcontinuum $N$ of $H$ such that $p \in\left(\right.$ int $\left._{H} N\right)$ and $N \subset H-\{s\}$. Then $V=\left[\left(\operatorname{int}_{H} N\right) \cap(\right.$ int $\left.H)\right]$ is open in $M$ and $p \in V \subset$ $N \subset M-S^{\prime}$. This implies that $M$ is aposyndetic at $p$ with respect to $S^{\prime}$ which is a contradiction.

Case II. $p$ separates $M$. Let $A$ and $B$ be disjoint open sets such that $M-\{p\}=A \cup B$. Then $A \cup\{p\}$ and $B \cup\{p\}$ are proper subcontinua of $M$.

(i) Suppose $S^{\prime} \cap B=\varnothing$. Let $H^{\prime}=H \cup(B \cup\{p\})$. Then $H^{\prime}$ and $A \cup\{p\}$ 
are proper subcontinua of $M$ and $M=H^{\prime} \cup(A \cup\{p\})$. Thus $H^{\prime}$ is aposyndetic so there is a subcontinuum $N$ of $H^{\prime}$ such that $p \in\left(\right.$ int $\left._{H^{\prime}} N\right)$ and $N \subset\left(H^{\prime}-\{s\}\right)$. Thus $p \in\left[\left(\right.\right.$ int $\left._{H^{\prime}} N\right) \cap($ int $\left.H)\right] \subset N \subset M-S^{\prime}$ implies that $M$ is aposyndetic at $p$ with respect to $S^{\prime}$.

Likewise, if $S^{\prime} \cap A=\varnothing$, then $M$ is aposyndetic at $p$ with respect to $S^{\prime}$.

(ii) Suppose $S^{\prime} \cap A \neq \varnothing \neq S^{\prime} \cap B$. Then both $\left(S^{\prime} \cap A\right)$ and $\left(S^{\prime} \cap B\right)$ are proper closed subsets of $S^{\prime}$. There are subcontinua $L$ and $N$ of $M$ such that $p \in$ int $L \subset L \subset M-\left(S^{\prime} \cap A\right)$ and $p \in$ int $N \subset N \subset M-\left(S^{\prime} \cap B\right)$. Now if $L \cap\left(S^{\prime} \cap B\right)=\varnothing$ or $N \cap\left(S^{\prime} \cap A\right)=\varnothing$, it follows that $M$ is aposyndetic at $p$ with respect to $S^{\prime}$. So assume that $L \cap\left(S^{\prime} \cap B\right) \neq \varnothing \neq N \cap\left(S^{\prime} \cap A\right)$. Let $M_{1}=(A \cup\{p\}) \cup N$ and $M_{2}=(B \cup\{p\}) \cup L$. Then $M_{1}$ and $M_{2}$ are proper subcontinua of $M$ and $M_{1} \cap M_{2}=[(A \cup\{p\}) \cap L] \cup[(B \cup\{p\}) \cap N]$ is a continuum. Thus $p \in[($ int $L) \cap($ int $N)] \subset\left(M_{1} \cap M_{2}\right) \subset M-S^{\prime}$ implies that $M$ is aposyndetic at $p$ with respect to $S^{\prime}$.

In either case a contradiction is reached, therefore $M$ is countable-set aposyndetic.

COROLlaRY 1. Every strongly aposyndetic rational curve is locally connected, hence a continuous curve.

A continuum $X$ is said to be hereditarily aposyndetic provided that every subcontinuum of $X$ is aposyndetic. In [6], hereditary aposyndesis was shown to be a necessary and sufficient condition for hereditary locally connectedness.

Question. Is every strongly aposyndetic continuum hereditarity aposyndetic?

In [3] Jones proved that the product of any pair of nondegenerate continua is aposyndetic and in [2] this result was extended to show that the product is countable-set aposyndetic. Although strongly aposyndetic continua are countable-set aposyndetic, we establish in Theorem 4 that no product of nondegenerate continua is strongly aposyndetic.

In order to prove this theorem we first establish the following lemma.

Lemma 1. Let $M$ be a continuum, $N$ be a subcontinuum of $M, q \in M-N$, and $I$ be a subcontinuum of $M$ that is irreducible between $q$ and $N$. If $I \cup N$ is aposyndetic, then $N$ is aposyndetic and $I$ is an arc.

Proof. Suppose $I \cup N$ is aposyndetic.

Assertion. $\quad I \cap N$ is a single point. For suppose this is not the case and let $p_{1}$ and $p_{2}$ be distinct points in $I \cap N$. Since $I$ is irreducible, $I-(I \cap N)$ is connected and each point of $I \cap N$ is a limit point of $I-(I \cap N)$. There is a subcontinuum $D$ of $I \cup N$ such that $p_{1} \in\left(\operatorname{int}_{I \cup N} D\right) \subset D \subset\left[(I \cup N)-\left\{p_{2}\right\}\right]$. It follows that (int $I \cup N D) \cap(I-N) \neq \varnothing$. Let $C$ be the composant of $q$ in $I$. Then $C \cap\left(\right.$ int $\left._{I \cup N} D\right) \cap(I-N) \neq \varnothing$ which implies that there is a proper subcontinuum $I^{\prime}$ of $I$ such that $q \in I^{\prime}$ and $I^{\prime} \cap\left(\right.$ int $\left._{I \cup N} D\right) \cap(I-N) \neq \varnothing$. 
Clearly $I^{\prime} \cap N=\varnothing$. Let $A$ be a subcontinuum of the continuum $D \cup I^{\prime}$ such that $A$ is irreducible between $q$ and $D \cap I \cap N$. Then $A-(D \cap I \cap N \cap A)$ is connected and each point of $D \cap I \cap N \cap A$ is a limit point of $A-$ $(D \cap I \cap N \cap A)$. Since $A \cap(N-I)$ and $A \cap(I-N)$ are mutually disjoint and $A-(D \cap I \cap N \cap A) \subset[A \cap(N-I)] \cup[A \cap(I-N)]$, it follows that $A-(D \cap I \cap N \cap A) \subset I$. Now $p_{2} \notin A$ so $A$ is a proper subcontinuum of $I$, $q \in A$, and $A \cap N \neq \varnothing$ which is a contradiction. Therefore $I \cap N$ is a single point and the assertion is established.

Now suppose $x$ and $y$ are points in $N$ and $x \neq y$. There is a subcontinuum $X$ such that $x \in\left(\right.$ int $\left._{I \cup N} X\right) \subset X \subset(I \cup N)-\{y\}$. Let $W$ be an open set in $M$ such that $\operatorname{int}_{I \cup N} X=W \cap(I \cup N)$. Then $U=W \cap N$ is open in $N$. Clearly $X \cap N$ is a subcontinuum of $N$ and $x \in U \subset X \cap N \subset N-\{y\}$. Thus $N$ is aposyndetic at $x$ with respect to $y$. Therefore $N$ is aposyndetic.

By interchanging the roles of $N$ and $I$ in the preceding argument we have that $I$ is also aposyndetic. Since $I$ is irreducible, $I$ is an arc [8].

THEOREM 4. If $M$ is the product of a pair of nondegenerate continua, then $M$ is not strongly aposyndetic.

Proof. Let $X$ and $Y$ be nondegenerate continua such that $M=X \times Y$ and suppose $M$ is strongly aposyndetic.

Case I. $X$ and $Y$ are decomposable. First we will construct proper subcontinua $H$ and $K$ of $M$ such that $M=H \cup K$.

Let $X_{1}, X_{2}$ be proper subcontinua of $X$ and $Y_{1}, Y_{2}$ be proper subcontinua of $Y$ such that $X=X_{1} \cup X_{2}$ and $Y=Y_{1} \cup Y_{2}$. Since $\operatorname{dim}\left(X_{1} \times Y_{1}\right) \geqq 2$ there is an indecomposable subcontinuum $N$ contained in $X_{1} \times Y_{1}$ [5]. Let $\Pi_{Y}$ be the projection map from $M$ onto $Y$ and let $z \in Y-\Pi_{Y}(N)$. Let $U$ be open in $Y$ such that $\Pi_{Y}(N) \subset U \subset \mathrm{Cl}(U) \subset Y-\{z\}$. Let $x \in X_{2}$ and $H=$ $(X \times \mathrm{Cl}(U)) \cup(\{x\} \times Y)$.

Let $y \in \Pi_{Y} N$ and let $I$ be a subcontinuum of $X \times\{y\}$ such that $I$ is irreducible between $(x, y)$ and $N \cap(X \times\{y\})$. Let $K=[X \times(Y-U)] \cup$ $(\{x\} \times Y) \cup I \cup N$.

Clearly $H$ and $K$ are proper subcontinua of $M$ and $M=H \cup K$, thus by supposition $K$ is aposyndetic.

Assertion. $\quad I \cup N$ is aposyndetic. For suppose $a$ and $b$ are distinct points in $I \cup N$. There is a subcontinua $L$ of $K$ such that $a \in\left(\right.$ int $\left._{K} L\right) \subset L \subset K-\{b\}$. Clearly $L \cap(I \cup N)$ is a continuum. There is a set $V$ open in $M$ such that int $_{K} L=K \cap V$. Then $W=V \cap(I \cup N)$ is open in $I \cup N$ and $a \in W \subset L \cap$ $(I \cup N) \subset(I \cup N)-\{b\}$ implies that $I \cup N$ is aposyndetic at the point $a$ with respect to the point $b$. Thus $I \cup N$ is aposyndetic and the assertion is established.

Since $I \cup N$ is aposyndetic, it follows from Lemma 1 that $N$ is aposyndetic. This implies that $N$ is decomposable which is a contradiction. 
Case II. Without loss of generality assume $X$ is indecomposable. Let $p$ and $q$ be distinct points of $X$ and $U$ be an open subset of $X$ such that $p \in U \subset(\mathrm{Cl} U) \subset X-\{q\}$. Let $y \in Y$. Then $H=((\mathrm{Cl} U) \times Y) \cup(X \times\{y\})$ and $K=[(X-U) \times Y] \cup(X \times\{y\})$ are proper subcontinua of $M$ and $M=H \cup K$.

Since $H$ is aposyndetic, there is a subcontinuum $L$ of $H$ such that $\{(p, y)\} \subset$ int $_{H} L \subset L \subset H-\{(q, y)\}$. It follows that $L \cap(\{q\} \times Y)=\varnothing$. Let $V$ be an open subset of $M$ such that int $_{H} L=V \cap H$ and let $\Pi_{X}$ be the projection map from $M$ onto $X$. Then $\Pi_{X}(V)$ is open in $X$ and $\Pi_{X}(L)$ is a subcontinuum of $X$. Since $p \in\left[\Pi_{X}(V) \cap U\right] \subset \Pi_{X}(L) \subset X-\{q\}, X$ contains a proper subcontinuum with nonempty interior which is contrary to $X$ being indecomposable.

In either case a contradiction is reached, therefore $M$ is not strongly aposyndetic.

From the proof of the preceding theorem it is readily seen that if $M$ is the product of a pair of nondegenerate continua there are proper subcontinua $H$ and $K$ such that $M=H \cup K$ and neither $H$ nor $K$ is aposyndetic.

Also, it is easily seen that if $M$ is a strongly aposyndetic continuum, $H$ and $K$ proper subcontinua of $M$ such that $M=H \cup K$, and $H_{1}, H_{2}$ are proper subcontinua of $H$ such that $H=H_{1} \cup H_{2}$, then either $H_{1}$ or $H_{2}$ is aposyndetic.

It follows from these remarks that if $M_{1}$ is the product of a pair of nondegenerate continua and $M_{2}$ is any continuum such that $M_{1} \cap M_{2} \neq \varnothing$, then $M_{1} \cup M_{2}$ is not strongly aposyndetic.

If the answer to the question raised above is in the affirmative, then every strongly aposyndetic continuum is hereditarily decomposable and hereditarily arcwise connected.

Some weaker forms of these two properties are established in the remaining portion of this paper.

THEOREM 5. Suppose $M$ is a strongly aposyndetic continuum, $N$ is a nondegenerate subcontinuum of $M$, and $p$ is a point of $N$. Then $N$ contains an arc containing $p$.

Proof. Let $q \in N-\{p\}$. Since $M$ is fully decomposable [3], there exist subcontinua $H$ and $K$ such that $p \in H-K, q \in K-H$, and $M=H \cup K$.

Let $A$ be a subcontinuum of $K \cup N$ which is irreducible from $p$ to $K$. Then $K \cup A$ is aposyndetic so by Lemma $1, A$ is an arc. Also since $A-(A \cap K) \subset N$, it follows that $A \subset N$ and the proof is complete.

THeOrem 6. Suppose $M$ is a strongly aposyndetic continuum, $H$ and $K$ are proper subcontinua whose sum is $M$, and $N$ is an indecomposable subcontinuum of $M$. Then $H$ intersects each composant of $N$. 
Proof. Suppose $C$ is a composant of $N, C \subset K-H$, and let $q \in C$.

Case I. $N \cap H \neq \varnothing$. Then $N \cup H$ is an aposyndetic subcontinuum of $M$. Since $N$ is a subcontinuum of $N \cup H$ which is irreducible (in $N \cup H$ ) from $q$ to $H$, it follows from Lemma 1 that $N$ is an arc. This is a contradiction since $N$ is indecomposable.

Case II. $\quad N \cap H=\varnothing$. Let $A$ be a subcontinuum of $K$ which is irreducible from $(K \cap H)$ to a point $p$ in $N-C$. Then $(H \cup A)$ and $(H \cup A \cup N)$ are aposyndetic subcontinua of $M$. Since $A$ is irreducible (in $H \cup A$ ) from $p$ to $H$, it follows from Lemma 1 that $A$ is an arc. Also $(A \cup N)$ is irreducible (in $H \cup A \cup N$ ) from $q$ to $H$, thus by Lemma $1, A \cup N$ is an arc. This is again a contradiction since $N$ is indecomposable.

Therefore $C \cap H \neq \varnothing$ and the theorem is established.

COROLlary 2. If $N$ is an indecomposable subcontinuum of the strongly aposyndetic continuum $M$, then every subcontinuum of $M$ with interior intersects every composant of $N$.

Proof. Suppose $N$ is an indecomposable subcontinuum of $M, H$ is a subcontinuum of $M$, and int $H \neq \varnothing$.

If $H$ does not separate $M$, then $M=H \cup \mathrm{Cl}(M-H)$; so, by Theorem 6, $H$ intersects each composant of $N$.

Suppose $H$ separates $M$. Let $S$ and $T$ be disjoint open sets in $M$ such that $M-H=S \cup T$. Then $(H \cup S)$ and $(H \cup T)$ are proper subcontinua whose sum is $M$. Let $C$ be a composant of $N$. By Theorem 6, $C \cap(H \cup S) \neq$ $\varnothing \neq C \cap(H \cup T)$ and since $C$ is connected it follows that $C \not S \cup T$. Thus $C \cap H \neq \varnothing$.

THEOREM 7. If the strongly aposyndetic continuum $M$ contains an indecomposable subcontinuum, then no countable subset of $M$ separates $M$.

Proof. Suppose $N$ is an indecomposable subcontinuum of $M$ and $S$ is a countable point set which separates $M$. Let $A$ and $B$ be separated sets such that $M-S=A \cup B$. Let $a \in A$ and $b \in B$. Since $M$ is countable-set aposyndetic (Theorem 3) there are subcontinua $H$ and $K$ such that $a \in$ int $H \subset H \subset M-S$ and $b \in$ int $K \subset K \subset M-S$. Clearly $H \subset A$ and $K \subset B$. Now by Corollary 2, each composant of $N$ intersects both $H$ and $K$. Hence each composant of $N$ intersects $S$. This is a contradiction since the family of composants of $N$ is an uncountable collection of pairwise disjoint sets.

We are now able to conclude that strongly aposyndetic continua are one-dimensional.

THEOREM 8. Let $M$ be a strongly aposyndetic continuum. Then $\operatorname{dim} M=1$. 
Proof. Suppose $\operatorname{dim} M>1$. Then there is a point $p \in M$ such that the dimension of $M$ at $p$ is greater than one. Let $q \in M-\{p\}$. Since $X$ is fully decomposable [3], there are subcontinua $H$ and $K$ such that $p \in H-K$, $q \in K-H$, and $M=H \cup K$. Let $U$ be an open set such that $p \in U \subset \bar{U} \subset H-K$. Since $\operatorname{dim} \bar{U}>1$, there is an indecomposable subcontinuum $N$ such that $N \subset \bar{U}$ [5]. Clearly $K$ does not intersect each composant of $N$ which contradicts Corollary 2.

Therefore $\operatorname{dim} M=1$.

\section{REFERENCES}

1. Donald E. Bennett, Aposyndetic properties of unicoherent continua, Pacific J. Math. 37 (1971), 585-589.

2. R. W. Fitzgerald, The cartesian product of non-degenerate compact continua is npoint aposyndetic, Topology Conference (Arizona State Univ., Tempe, Ariz., 1967), Arizona State Univ., Tempe, Ariz., 1968, pp. 324-326. MR 38 \#5155.

3. F. B. Jones, Aposyndetic continua and certain boundary problems, Amer. J. Math. 63 (1941), 545-553. MR 3, 59.

4. K. Kuratowski, Topologie. Vol. II, PWN, Warsaw, 1961; English transl., Academic Press, New York; PWN, Warsaw, 1968. MR 24 \#A2958; MR 41 \#4467.

5. S. Mazurkiewicz, Sur l'existence des continus indécomposables, Fund. Math. 25 (1935), 327-328.

6. E. J. Vought, A classification scheme and characterization of certain curves, Colloq. Math. 20 (1969), 91-98. MR 38 \#6550.

7. - n-aposyndetic continua and cutting theorems, Trans. Amer. Math. Soc. 140 (1969), 127-135. MR 39 \#3462.

8. G. T. Whyburn, Semi-locally-connected sets, Amer. J. Math. 61 (1939), 733-749. MR 1, 31.

9. - Analytical topology, Amer. Math. Soc. Colloq. Publ., vol. 28, Amer. Math. Soc., Providence, R.I., 1942. MR 4, 86.

Department of Mathematics, Murray State University, Murray, Kentucky 42071 